James Madison University JMU Scholarly Commons

Masters Theses

The Graduate School

Spring 2017

\title{
Physiological differences in cardiovascular hemodynamics across treadmill and cycle exercise as assessed through impedance cardiography
}

Daniel S. Valcicak

James Madison University

Follow this and additional works at: https://commons.lib.jmu.edu/master201019

Part of the Sports Sciences Commons

\section{Recommended Citation}

Valcicak, Daniel S., "Physiological differences in cardiovascular hemodynamics across treadmill and cycle exercise as assessed through impedance cardiography" (2017). Masters Theses. 514.

https://commons.lib.jmu.edu/master201019/514

This Thesis is brought to you for free and open access by the The Graduate School at JMU Scholarly Commons. It has been accepted for inclusion in Masters Theses by an authorized administrator of JMU Scholarly Commons. For more information, please contact dc_admin@jmu.edu. 
Physiological Differences in Cardiovascular Hemodynamics across Treadmill and Cycle Exercise Assessed through Impedance Cardiography

\author{
Daniel Valcicak
}

A thesis submitted to the Graduate Faculty of

\title{
JAMES MADISON UNIVERSITY
}

in partial fulfillment of the requirements for the degree of

Master of Science

Department of Kinesiology

May 2017

FACULTY COMMITTEE:

Committee Chair: Trent A. Hargens, Ph.D.

Committee Members/ Readers:

Michael J. Saunders, Ph.D.

Christopher J. Womack, Ph.D. 


\section{Acknowledgements}

I would like to thank my thesis chair, Dr. Trent Hargens. Without your help and guidance, this project would not be possible. Words cannot express how grateful I am for being granted this opportunity.

I would like to thank the rest of my committee members: Dr. Michael Saunders and Dr. Christopher Womack. I appreciate all your input and support through the process.

I would like to thank my friends and collegues at JMU, including Taylor Landry, Kevin Decker, Erin Horil, Annette Lemanski, Paul Roberson, Gabe Giersch, Ryan Martin, John Chase, Jess Ehrbar, Jeremy Via, DJ Velky, and David Lenzi. Each one of you has made my time at JMU unforgettable. Furthermore, I want to thank to Dr. Nicholas Luden for his advising, both inside and outside the academic setting. His wise words always kept things in perspective.

Additionally, I would like to thank Lindsey Rodriguez for her time and dedication to this project. Your presence at every trial was monumental in the data collection process. Without you, this project would not have been so successful.

I would like to thank my family, especially my mother and father, Joan and Marty. Your unconditional love and support is overwhelming, and the opportunities you have given me have always inspired me to put forth my best efforts (A.M.D.G.).

Lastly, thank you to the subjects for their time and efforts. Their willingness to volunteer will always have my eternal gratitude. 


\section{Table of Contents}

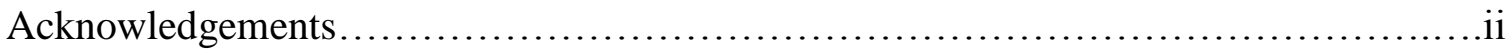

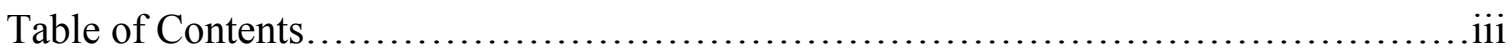

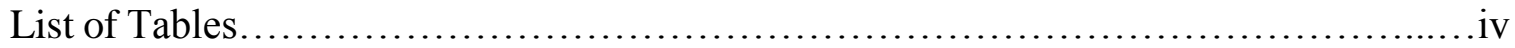

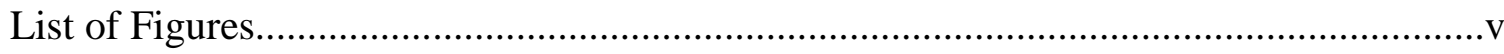

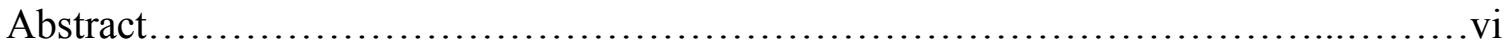

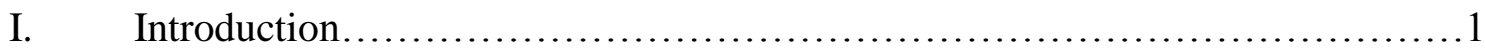

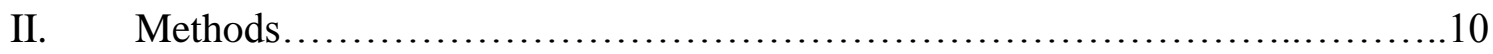

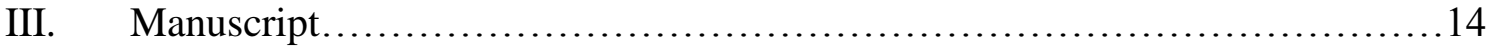

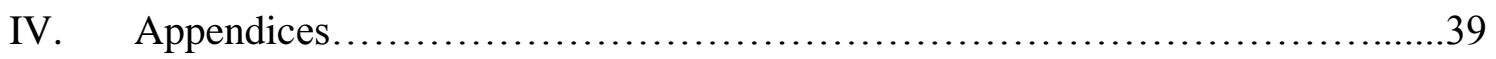

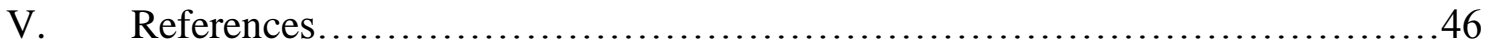




\section{List of Tables}

Table 1. Treadmill and Cycling Protocols........................................... 31

Table 2. Subject Characteristics........................................... 32

Table 3. Mean Values of Principle Hemodynamic Variables.........................33

Table 4. Mean Values of Secondary Hemodynamic Variables.........................34 


\section{List of Figures}

Figure 1. HR Response from MODex to VIGex................................... 35

Figure 2. SV Response from MODex to VIGex ................................. 36

Figure 3. EDV Response from MODex to VIGex .................................... 37

Figure 4. CTi Response from MODex to VIGex........................................ 


\begin{abstract}
Impedance cardiography (IC) measures cardiovascular hemodynamics noninvasively during exercise. However, IC measurements assessing physiological differences across treadmill (TM) and cycle (CYC) exercise has not been investigated. The purpose of this study is to investigate whether hemodynamic measurements assessed via IC are consistent between TM and CYC exercise at two absolute exercise intensities. Twenty-one men $($ age $=21.4 \pm 0.5 \mathrm{y} ; \mathrm{BMI}=24.4 \pm 0.5)$ completed four exercise tests, two TM and two CYC. Within each test, two, five-minute, steady-state stages were completed with targeted intensities of 5 (MODex) and 7 (VIGex) metabolic equivalents (METs). Oxygen consumption $\left(\mathrm{VO}_{2}\right)$ was measured by indirect calorimetry. Hemodynamic measures were obtained via IC (PhysioFlow, PF07 Enduro) and included cardiac output (CO), heart rate (HR), stroke volume (SV), end diastolic volume (EDV), ejection fraction (EF), systemic vascular resistance (SVR), contractility index (CTi), and left cardiac work index (LCWi). Within treadmill exercise, there were no main effects for trial, except for HR. There were no main effects for trial within CYC exercise. Across exercise modes, there were no significant differences between TM and CYC exercise for all variables, with the exception of higher HR in CYC, and higher SV and EDV in TM. ICCs were strong for all variables except VIGex SVR and VIGex LCWi. IC hemodynamic measurements showed strong repeatability across modes for all hemodynamic variables during MODex. For VIGex, all variables showed strong correlations, except for SVR and LCWi. Lack of agreement may be associated with daily variation in hemodynamics or physiological differences across modes with the remainder of discrepancies associated with device error.
\end{abstract}




\section{Chapter 1}

\section{Introduction}

\section{Hemodynamics during Exercise}

In cardiovascular physiology, hemodynamics relates to blood circulation. The heart ejects blood each beat in order to deliver oxygen throughout the body. The amount of blood pumped into the aorta per beat is known as stroke volume (SV), which when multiplied by heart rate $(\mathrm{HR})$ determines cardiac output $(\mathrm{CO})$ (American College of Sports Medicine and Ehrman, 2014). $\mathrm{CO}$ is the central limiting factor in an individual's $\mathrm{VO}_{2}$ max, which represents the greatest amount of oxygen that can be consumed and utilized in the muscle tissues. Average resting SV values range from $60-100 \mathrm{~mL} /$ beat. This discrepancy can be attributed to body size and training status (American College of Sports Medicine and Ehrman, 2014). Larger individuals will have a greater SV compared to smaller individuals. Furthermore, trained athletes will have a greater SV, compared to untrained individuals, due to increased blood volume allowing for a greater venous return and end diastolic volume (EDV), which stretches the myocardium causing a more efficient contraction compared to untrained individuals (Ekblom et al., 1968; American College of Sports Medicine and Ehrman, 2014). Likewise, endurance training increases left ventricular mass and compliance that leads to decreases in afterload and end systolic volume (ESV) producing a larger SV (Howden et al., 2015). Up to $40 \% \mathrm{VO}_{2} \max , \mathrm{SV}$ increases to 100$120 \mathrm{~mL} /$ beat in the average person. Beyond that point, increases in HR have a greater influence on the increases in CO (Ekblom et al., 1968; American College of Sports Medicine and Ehrman, 2014). In endurance trained athletes, SV may reach $200 \mathrm{~mL} /$ beat through maximal exercise without a plateau leading to greater $\mathrm{CO}$ compared to untrained 
individuals (Gledhill, Cox and Jamnik, 1994). There are several methods that can be used to measure $\mathrm{CO}$.

\section{$\underline{\text { Measuring Cardiac Output }}$}

The direct Fick method and dye dilution are considered the "gold standards" for measuring CO (Warburton et al., 1999). Both methods use catheters in or near the heart. The direct Fick method allows for the simultaneous collections of arterial and venous blood, so the atrial-venous oxygen difference $\left(\mathrm{a}-\mathrm{vO}_{2}\right)$ can be calculated. $\mathrm{SV}$ can then be calculated using the Fick Equation since HR is known (Cournand et al., 1945). In the dye dilution technique, a known amount of dye is injected into the vena cava or pulmonary artery. A densitometer measures the downstream blood flow calculating SV from the change in fluid density (Ekblom et al., 1968). Thermodilution is a similar technique to dye dilution, but a cold solution of a given temperature is injected instead of dye. The change in temperature of the infused solution is used to calculate SV (Scherhag, Kaden and Kentschke, 2005). Although these methods are considered valid (Cournand et al., 1945; Ekblom et al., 1968; Warburton et al., 1999), their invasive nature can make them difficult to utilize during exercise. These issues led to the development several of non-invasive $\mathrm{CO}$ measuring techniques.

Non-invasive methods used to calculate $\mathrm{CO}$ include $\mathrm{CO}_{2}$ rebreathing (Faulkner et al., 1971), acetylene rebreathing (Bell et al., 2003), inert gas rebreathing (Siebenmann et al., 2015), doppler echocardiography (Bogui et al., 2013), pulse contour analysis (Siebenmann et al., 2015), and impedance cardiography (Kubicek et al., 1966; Sramek, 1982; Bernstein, 1986; Charloux et al., 2000). 
$\mathrm{CO}_{2}$ rebreathing requires the subject to inhale a known concentration of $\mathrm{CO}_{2}$ to create equilibrium with the lungs. At which point, a pulse oximeter or arterial blood sample can be used to determine the concentration of arterial $\mathrm{O}_{2}$. By using the Fick Equation, $\mathrm{CO}$ can be estimated (Faulkner et al., 1971).

Acetylene rebreathing requires a known mixture of gas to be inhaled by the subjects. Three breaths are required to achieve equilibrium between the gas supply and the lungs. Inert gas rebreathing follows a similar concept where the inert gas diffused into the blood, but does not bind with hemoglobin. The rate at which the concentrations of gas decreases from the source is proportional to CO (Bell et al., 2003; Siebenmann et al., 2015).

Doppler echocardiography uses sound waves and ultrasound imaging to measure left ventricle cross-sectional area. SV per cardiac cycle is estimated to be the difference in cross-sectional measurements between EDV and ESV (Bogui et al., 2013).

Pulse contour analysis measures SV using a fingertip clamp to analyze the arterial impedance per pulse beat. The changes in pulse systolic area is used to estimate CO. Although this method is considered non-invasive, thermodilution is used to calibrate the device (Siebenmann et al., 2015).

Impedance cardiography (ICG) is a similar concept to pulse contour analysis. However, the impedance is measured in the thoracic region, and the calibration process does not entail an invasive component. ICG attempts to continually measure CO through a noninvasive technique based off Ohm's Law, which states that Resistance $=$ Voltage / ampere. Electrical current will travel the path of least resistance, so as the heart ejects blood from the left ventricle, the current is "absorbed" by the ejected blood. The degree of absorption is used to calculate SV. 


\section{$\underline{\text { Hemodynamics across Treadmill and Cycle Exercise }}$}

When comparing treadmill and cycle exercise at a given $\mathrm{HR}$, percent $\mathrm{VO}_{2}$ max of the given mode is statistically higher in cycling compared to treadmill exercise (McArdle and Magel, 1970). When comparing treadmill and cycle exercise at a given $\mathrm{VO}_{2}, \mathrm{CO}$ is equal across modes; however, this is a result of greater SV in running compared to a higher HR in cycling at the given intensity (Hermansen, Ekblom and Saltin, 1970). Furthermore, at a given percent of $\mathrm{VO}_{2}$ max, mean arterial pressure (MAP) was no difference across exercise modes (Hermansen, Ekblom and Saltin, 1970).

At maximal exercise, $\mathrm{CO}$ is greater in running due to a greater $\mathrm{SV}$ with equivalent maximal heart rates across modes, which allows for 6-11\% more oxygen uptake in treadmill exercise (Hermansen, Ekblom and Saltin, 1970; Faulkner et al., 1971). Furthermore, MAP can be $10 \%$ greater in maximal cycling compared to maximal treadmill exercise (Hermansen, Ekblom and Saltin, 1970). To compare hemodynamic measures across exercise modes at submaximal and maximal intensities, Hermansen and Faulker used dye dilution and $\mathrm{CO}_{2}$ rebreathing techniques, respectively.

\section{$\underline{\text { ICG History }}$}

Nyboer (Nyboer, Kreider and Hannapel, 1950) first implemented this practice by placing two metal strips proximally and two strips distally on the subjects' extremities to measure the change in blood volume. This concept was later adopted by Kubicek in the 1960s to measure stroke volume by repositioning the metal strips to the neck and around the xiphoid region (Kubicek et al., 1966). These metal strips act as conducting and sensing electrodes; the upper most strip on the neck and the bottom most strip on the thorax conduct 
a low amplitude, high frequency current while the bottom strip on the neck and top strip on the thorax read the changes in volume by this equation:

$$
S V=\rho * \frac{L^{2}}{Z i^{2}} * \frac{d Z}{d t_{\max }}
$$

Where $\rho=$ the electrical resistivity of blood at $100 \mathrm{kHz}$ (which has an average value of 150 ohm-cm); $\mathrm{L}=$ the mean distance between the two inner electrodes in $\mathrm{cm} ; \mathrm{Zi}=$ the impedance between the two inner electrodes in ohms; and $\mathrm{dZ}=$ the extrapolated maximum impedance change during systole (Kubicek et al., 1966). When using Kubicek's equation for ICG, it must be assumed that the thorax is cyndrical in shape. In the 1980s, Sramek critiqued Kubicek's equation by creating a constant for blood resistivity and altering the thoracic shape to be a truncated cone to provide more accurate measurements (Sramek, 1982):

$$
S V=\frac{C^{2} L T * d Z / s e c}{37 * Z i}
$$

Where $\mathrm{C}=$ the average thoracic circumference at the xiphoid processes in $\mathrm{cm} ; \mathrm{L}=$ the average distance between the sensing electrodes in $\mathrm{cm} ; \mathrm{Zi}=$ thoracic impedance in ohms; $\mathrm{T}=$ ventricular ejecting time in seconds, and $\mathrm{dZ} / \mathrm{sec}$ is the maximum rate of impedance change in ohms/sec. When impedance cardiographs are designed to use the Sramek equation, SV values were underestimated when the individual was 15-20\% overweight; as a result, Berstein altered the equation further to enhance ICG accuracy by accounting for the individual's body size (Bernstein, 1986):

$$
S V=\delta * \frac{(0.17 H)^{3}}{4.2} * T * \frac{d Z / d t_{\max }}{Z i}
$$


Where $\delta$ is the weight correction factor for the individual and $\mathrm{H}$ is height in $\mathrm{cm}$. Though different non-invasive methods, including ICG, are available to measure stroke volume, use of these methods compromises validity.

In recent years, a new ICG device, known as the PhysioFlow, has been developed to continually measure hemodynamics at rest and during exercise. These hemodynamic measures include $\mathrm{CO}$, cardiac index $(\mathrm{CI}), \mathrm{SV}$, stroke volume index (SVi), ventricular ejection time (VET), estimated ejection fraction (EF), estimated end diastolic volume (EDV), and systemic vascular resistance (SVR) (Charloux et al., 2000). CI and SVi are measures of $\mathrm{CO}$ and $\mathrm{SV}$, respectively, that are normalized to the body surface area (BSA) of an individual.

The PhysioFlow uses six electrodes: two above the supraclavicular fossa, two level with the xiphoid processes left of the spine, and two ECG electrodes located at V1 and V6 (Charloux et al., 2000). Unlike previous ICG devices, the electrodes placed on xiphoid processes can vary, and the recorded values will retain similar values $(r=0.995)$ (Tan, Lai and Hwang, 2006).

The formula that calculates the hemodynamics slightly differs from previous ICG devices (Charloux et al., 2000):

$$
C O=f_{c} * S V i * B S A
$$

Where $f_{c}$ is the heart rate of the subject in beats per minute calculated off the R-R interval of the ECG leads. Body mass and height are entered into the device, allowing the PhysioFlow to calculate BSA. The high frequency of $75 \mathrm{kHz}$ and low amplitude of $1.8 \mathrm{~mA}$ is able to calculate the amount of blood ejected per cardiac cycle. Knowing the volume of blood pumped per beat in relation to the individual's body surface area allows for the 
PhysioFlow to calculate CO and SV. Greater details describing the algorithms used by the PhysioFlow have been described previously (Charloux et al., 2000).

\section{$\underline{\text { ICG Validity }}$}

Several studies have validated the PhysioFlow's measurements against the direct Fick Method (Richard et al., 2001; Tordi et al., 2004) and $\mathrm{CO}_{2}$ rebreathing (Tordi et al., 2004), and dye-dilution (Robach et al., 2008) in healthy (Richard et al., 2001; Tordi et al., 2004; Robach et al., 2008) as well as clinical populations (Charloux et al., 2000; Ferreira et al., 2012). In some cases, the PhysioFlow's measurements can over-estimate when compared to the direct Fick Method (Bougault, 2005; Siebenmann et al., 2015), inert gas rebreathing (Siebenmann et al., 2015), and pulse contour analysis (Siebenmann et al., 2015). On the other hand, the PhysioFlow's measurements have been underestimated when compared to single breath acetylene uptake method (Wang et al., 2014).

Researchers may opt to use the PhysioFlow due to the additional variables, other than CO, that can be recorded. The algorithm that the PhysioFlow uses calculates additional variables, such as left cardiac work index (LCWi), early diastolic filling ratio (EDFR), contractility index (CTi), and systemic vascular resistance index (SVRi). LCWi is the amount of work the left ventricle must produce to eject blood in relation to the individual's BSA. EDFR is the ratio of peak left ventricle filling between early and late diastole. CTi is the heart's force production, independent of preload and afterload. SVRi is the afterload of a cardiac cycle in relation to BSA. These variables are continuously recorded through the duration of exercise. Having the capability to analyze multiple variables with a single device can save time, money, and effort of staff in a given setting. 
$\underline{\text { Purpose }}$

To date, no study has assessed the physiological differences across treadmill and cycle exercise using PhysioFlow ICG. Therefore, the purpose of the present study is to investigate whether hemodynamic measures assessed via PhysioFlow impedance cardiography are consistent within and across running and cycling exercise tests at two absolute submaximal intensities. It is hypothesized that the PhysioFlow impedance cardiography measures within an exercise mode will be high (ICC $\geq 0.7$ ). However, it is hypothesized that SV during running will be higher compared to cycling.

\section{Assumptions}

It is assumed that all subjects followed pre-test instructions of fasting and abstaining from caffeine and alcohol four hours prior to testing as well as refrained from strenuous exercise 24 hours prior to testing. It must be assumed that the ACSM metabolic equations are accurate as the cycling protocol will be tailored to each subject due to differences in body weight from subject to subject.

\section{Limitations}

The sample of subjects in this study was not completely random as subjects were recruited through word-of-mouth recruiting and bulk-email requests advertising the need for subjects. The present study cannot validate the PhysioFlow due to lack of access to direct measurements, so the present study must rely on previous research to validate the device.

\section{Delimitations}


Delimitations of this study include the use of healthy male subjects, 18 years and older. Female hemodynamics vary throughout the different stages of the menstrual cycle causing variation that is difficult to control. Studies were performed at the same time of day to eliminate diurnal variation in hemodynamics within subjects. 


\section{Chapter 2}

\section{Methodology}

Subjects

Twenty-one $(n=21)$ male subjects, who were all apparently healthy with no previous diagnosis of cardiovascular, pulmonary, or metabolic disease were recruited from the James Madison University campus. Females were not recruited due to hormonal changes in the menstrual cycle that could lead to decreased systemic vascular resistance altering hemodynamics (Chapman et al., 1997). Individuals who could not participate in vigorous exercise due to orthopedic limitations were also excluded from the study. All experimental protocols were approved by the Institutional Review Board for Human Subject Research at James Madison University prior to testing. All subjects completed the informed consent prior to participation.

Pre-test

Subjects were asked to visit JMU's Human Performance Lab on four separate occasions for approximately 1 hour each visit. Subjects were fasted and abstained from caffeine and alcohol for four hours prior to testing. Subjects were given two questionnaires to complete: the Physical Activity Readiness Questionnaire (PARQ) and the International Physical Activity Questionnaire, Short Form (IPAQ). The PARQ was completed to ensure subjects were cleared for exercise. IPAQ was administered to obtain self-reported physical activity levels. Subject height and weight were recorded to the nearest $0.5 \mathrm{~cm}$ and $0.1 \mathrm{~kg}$, respectively. 


\section{Hemodynamic Measures}

Hemodynamic variables were measured using the PhysioFlow (PF07 Enduro, Manatec Biomedical; Paris, France). Primary hemodynamic variables included CO, HR, and SV. Secondary variables consisted of end diastolic volume (EDV), ejection fraction (EF), systemic vascular resistance (SVR), contractility index (CTi), and left cardiac work index (LCWi). Six electrodes were used for this device: two electrodes placed above the supraclavicular fossa, two placed just left of the spine dorsally in line with the xiphoid processes, and two ECG electrodes (V1 and V6). Prior to electrode placement, each site was shaved to remove body hair, alcohol pads then cleaned the site, and lastly skin prep gel was applied in the specific area to lower impedance and improve signal quality. After electrodes were placed in the proper sites, subjects laid in the supine position for resting blood pressure measurements in accordance with the ACSM guidelines (American College of Sports Medicine, 2013). Thereafter, the PhysioFlow was auto-calibrated after 30 heart cycles. Blood pressure was measured a second time in the position of exercise (i.e. standing or sitting on cycle ergometer) prior to testing. The PhysioFlow recorded hemodynamic measures in 10 second averages at rest and throughout the exercise test in addition to a 3 minute recovery period.

Exercise Tests

Subjects performed a total of four graded exercise tests, two on a treadmill (TM1 and TM2) and two on an electronically braked cycle ergometer (CYC1 and CYC2). Oxygen consumption was measured through indirect calorimetry via a metabolic cart (Parvo Medics TrueOne 2400; Sandy, UT). TM1 was designated as the first visit while the 
final three tests were conducted in a randomized order. All four tests were completed with a minimum of 48 hours between tests and occurred at the same time of day for each subject. The custom treadmill protocol was established as follows: 2.6mph @ 0\% (1min), 3.1mph @ 1.5\% (1 min), 3.6mph @ 2.5\% (5 min), 4mph @ 3.5\% (1 min), 4mph @ 5.5\% (5min), 5mph@1\%(1min), 5.3mph@2.5\% (1min), 5.6mph@5\%(1min),6.1mph@6.5\% (1min),6mph@10.5\% (1min),6mph @14\%(1min),6mph@16.5\%,6.2mph @ 17.5\%, and 6.4mph@18.5\% (if reached, until exhaustion).

The cycling test protocol will be as follows: 2 METs ( $1 \mathrm{~min}), 3.4$ METs (1 min), 5 METs (5 min), 6.4 METs (1 min), 7 METs (5 min), 8.4 METs (1 min), 9.8 METs (1 min), 11.2 METs (1 min), 12.6 METs (1 min), 14 METs (1 min), 15.4 METs (1 min), and 16.8 METs (if reached, until fatigue). Watts for the given METs will be estimated using the metabolic equations (American College of Sports Medicine, 2013).

Subjects exercised to volitional exhaustion, an inability to maintain 60 revolutions per minute on the cycle ergometer, or if the subject reported any adverse effects as outlined in the ACSM Guidelines (American College of Sports Medicine, 2013). The two 5-minute stages corresponded to moderate and vigorous exercise (MODex and VIGex) with targeted intensities of 5 and 7 METs, respectively (American College of Sports Medicine, 2013). CYC1 and CYC2 MET levels for a give stage were estimated using the metabolic equations (American College of Sports Medicine, 2013). Blood pressure was measured 3 minutes into the steady-state stages. PhysioFlow data during the final 2 minutes of MODex and VIGex stages were averaged together to examine the PhysioFlow's test re-test reliability.

Cycling watt intensity for MODex and VIGex were estimated from TM1's averaged $\mathrm{VO}_{2}$ at the respective stage. These estimations were confirmed with $\mathrm{VO}_{2}$ 
measurements during the cycling tests. If the subject did not achieve the desired $\mathrm{VO}_{2}$ value within 2 minutes of the MODex and VIGex stages, watts were adjusted accordingly to mimic $\mathrm{TM} 1 \mathrm{VO}_{2}$ values at the respective stages. This was done to ensure $\mathrm{VO}_{2}$ was equal across treadmill and cycle exercise for the respective stages.

\section{Statistical Analyses}

Two-way ANOVAs with a Bonferroni correction were used to determine main effects for trial and intensity within an exercise mode. For across mode analysis, a twoway ANOVA with Bonferroni correction was used to determine main effects for mode and intensity for the averages of the TM trials and the averages of the CYC trials. Intraclass correlation coefficients (ICC) determined the agreement within and across exercise modes at the absolute submaximal intensities. Coefficients of variation (CV) were used to determine the variability within and across exercise trials. Statistical significance was set a priori at $\mathrm{p}<0.05$. 


\section{Chapter 3}

\section{Manuscript}

Physiological Differences in Cardiovascular Hemodynamics across Treadmill and Cycle Exercise as Assessed through Impedance Cardiography

Authors: Daniel S. Valcicak, Lindsey M. Rodriguez, Michael J. Saunders, Christopher J.

Womack, Trent A. Hargens

Institution: James Madison University, Harrisonburg, Virginia, 22807

Contacts: Daniel S. Valcicak, valcicds@dukes.jmu.edu

Lindsey M. Rodriguez, rodri2lm@dukes.jmu.edu

Michael J. Saunders, saundemj@jmu.edu

Christopher J. Womack, womackcx@jmu.edu

Trent A. Hargens, hargenta@jmu.edu

Address of Correspondence

Trent A. Hargens, Ph.D.

Department of Kinesiology

James Madison University

Harrisonburg VA, 22807

Phone: (540) 568-6145

Email: $\underline{\text { hargenta@jmu.edu }}$ 


\begin{abstract}
Impedance cardiography (IC) measures cardiovascular hemodynamics noninvasively during exercise. However, IC measurements assessing physiological differences across treadmill (TM) and cycle (CYC) exercise has not been investigated. The purpose of this study is to investigate whether hemodynamic measurements assessed via IC are consistent between TM and CYC exercise at two absolute exercise intensities. Twenty-one men $($ age $=21.4 \pm 0.5 \mathrm{y} ; \mathrm{BMI}=24.4 \pm 0.5)$ completed four exercise tests, two TM and two CYC. Within each test, two, five-minute, steady-state stages were completed with targeted intensities of 5 (MODex) and 7 (VIGex) metabolic equivalents (METs). Oxygen consumption $\left(\mathrm{VO}_{2}\right)$ was measured by indirect calorimetry. Hemodynamic measures were obtained via IC (PhysioFlow, PF07 Enduro) and included cardiac output (CO), heart rate (HR), stroke volume (SV), end diastolic volume (EDV), ejection fraction (EF), systemic vascular resistance (SVR), contractility index (CTi), and left cardiac work index (LCWi). Within treadmill exercise, there were no main effects for trial, except for HR. There were no main effects for trial within CYC exercise. Across exercise modes, there were no significant differences between TM and CYC exercise for all variables, with the exception of higher HR in CYC, and higher SV and EDV in TM. ICCs were strong for all variables except VIGex SVR and VIGex LCWi. IC hemodynamic measurements showed strong repeatability across modes for all hemodynamic variables during MODex. For VIGex, all variables showed strong correlations, except for SVR and LCWi. Lack of agreement may be associated with daily variation in hemodynamics or physiological differences across modes with the remainder of discrepancies associated with device error.
\end{abstract}




\section{Introduction}

In cardiovascular physiology, cardiac output $(\mathrm{CO})$ is the product of stroke volume (SV) and heart rate (HR) and is a central limiting factor in an individual's maximal oxygen consumption $\left(\mathrm{VO}_{2} \max \right)$ (American College of Sports Medicine and Ehrman, 2014). Resting SV ranges from $60-100 \mathrm{~mL} /$ beat, with body size and training status being the most influential factors (American College of Sports Medicine and Ehrman, 2014). While exercising, a HR of 120 beats per minute (bpm) is typically the threshold of SV plateau at $120 \mathrm{~mL} / \mathrm{beat}$; however, endurance trained athletes may achieve values as high as 200mL/beat with no plateau through maximal exercise (Gledhill, Cox and Jamnik, 1994). Additionally, exercise mode can influence $\mathrm{CO}$ dynamics. At a given $\mathrm{VO}_{2}, \mathrm{CO}$ is equal between treadmill and cycling; however, this is a result of higher SV in running compared to a higher HR in cycling at the given intensity (Hermansen, Ekblom and Saltin, 1970). At maximal exercise, $\mathrm{CO}$ is greater in running due to a greater $\mathrm{SV}$ with equivalent maximal heart rates across modes (Hermansen, Ekblom and Saltin, 1970; Faulkner et al., 1971).

There are several methods used to determine CO. The direct Fick method and dye dilution have been considered the "gold standard" methods (Warburton et al., 1999). Though these techniques are considered the most valid, their invasive nature can become difficult and risky during exercise due to catheters inserted in or near the heart (Warburton et al., 1999). This issue led to the development of several non-invasive methods, including carbon dioxide $\left(\mathrm{CO}_{2}\right)$ rebreathing, acetylene rebreathing, inert gas rebreathing, Doppler echocardiography, pulse contour analysis, and impedance cardiography (ICG). Of these, ICG is the only non-invasive technique allowing for continual recording of hemodynamics. 
ICG is based off Ohm's Law with the concept first introduced by Nyboer (Nyboer, Kreider and Hannapel, 1950) and later developed by Kubicek (Kubicek et al., 1966) to measure thoracic impedance. Sramek (Sramek, 1982) and Bernstein (Bernstein, 1986) refined the technique further, accounting for thoracic volume and body size, respectively.

Most recently, an ICG device, known as the PhysioFlow, has been developed to continually measure hemodynamics at rest and during exercise and has been validated against the direct Fick method (Charloux et al., 2000; Richard et al., 2001) and dye dilution (Robach et al., 2008). To date, no study has tested the physiological differences across exercise modes at absolute submaximal intensities using PhysioFlow ICG. Therefore, the purpose of the present study was to investigate whether hemodynamic measures assessed via PhysioFlow impedance cardiography were consistent across running and cycling exercise tests at two absolute submaximal intensities. It was hypothesized that the PhysioFlow impedance cardiography measures within an exercise mode will be reproducible (ICC $\geq 0.7$ ). However, it was hypothesized that stroke volume during running will be higher compared to cycling.

\section{Methods}

\section{Subjects}

Twenty-one $(n=21)$ male subjects, who were all apparently healthy with no previous diagnosis of cardiovascular, pulmonary, or metabolic disease were recruited from the James Madison University campus. Females were not recruited due to hormonal changes in the menstrual cycle that could lead to decreased systemic vascular resistance altering hemodynamics (Chapman et al., 1997). Individuals who could not participate in vigorous exercise due to orthopedic limitations were also excluded from the study. All 
experimental protocols were approved by the Institutional Review Board for Human Subject Research at James Madison University prior to testing. All subjects completed the informed consent prior to participation.

Pre-test

Subjects were asked to visit JMU's Human Performance Lab on four separate occasions for approximately 1 hour each visit. Subjects were fasted and abstained from caffeine and alcohol for four hours prior to testing. Subjects were given two questionnaires to complete: the Physical Activity Readiness Questionnaire (PARQ) and the International Physical Activity Questionnaire, Short Form (IPAQ). The PARQ was completed to ensure subjects were cleared for exercise. IPAQ was administered to obtain self-reported physical activity levels. Subject height and weight were recorded to the nearest $0.5 \mathrm{~cm}$ and $0.1 \mathrm{~kg}$, respectively.

\section{Hemodynamic Measures}

Hemodynamic variables were measured using the PhysioFlow (PF07 Enduro, Manatec Biomedical; Paris, France). Primary hemodynamic variables included CO, HR, and SV. Secondary variables consisted of end diastolic volume (EDV), ejection fraction (EF), systemic vascular resistance (SVR), contractility index (CTi), and left cardiac work index (LCWi). The six electrodes were used for the device and placed in identical fashion to previous literature (Charloux et al., 2000). Then subjects laid in the supine position for resting blood pressure measurements in accordance with the ACSM guidelines (American College of Sports Medicine, 2013). Thereafter, the PhysioFlow was auto-calibrated after 
30 heart cycles. Blood pressure was measured a second time in the position of exercise (i.e. standing or sitting on cycle ergometer) prior to testing. The PhysioFlow recorded hemodynamic measures in 10 second averages at rest and throughout the exercise test in addition to a 3-minute recovery period.

\section{Exercise Tests}

Subjects performed a total of four graded exercise tests, two on a treadmill (TM1 and TM2) and two on an electronically braked cycle ergometer (CYC1 and CYC2). Oxygen consumption was measured through indirect calorimetry via a metabolic cart (Parvo Medics TrueOne 2400; Sandy, UT). TM1 was designated as the first visit while the final three tests were conducted in a randomized order. All four tests were completed with a minimum of 48 hours between tests and occurred at the same time of day for each subject. The custom treadmill and cycle protocols can be seen in Table 1.

Subjects exercised to volitional exhaustion, an inability to maintain 60 revolutions per minute on the cycle ergometer, or if the subject reported any adverse effects as outlined in the ACSM Guidelines (American College of Sports Medicine, 2013). The two 5-minute stages corresponded to moderate and vigorous exercise (MODex and VIGex) with targeted intensities of 5 and 7 METs, respectively (American College of Sports Medicine, 2013). CYC1 and CYC2 MET levels for a give stage were estimated using the metabolic equations (American College of Sports Medicine, 2013). Blood pressure was measured 3 minutes into the steady-state stages. PhysioFlow data during the final 2 minutes of MODex and VIGex stages were averaged together for data analysis. 
Cycling watt intensity for MODex and VIGex were estimated from TM1's averaged $\mathrm{VO}_{2}$ at the respective stage. These estimations were confirmed with $\mathrm{VO}_{2}$ measurements during the cycling tests. If the subject did not achieve the desired $\mathrm{VO}_{2}$ value within 2 minutes of the MODex and VIGex stages, watts were adjusted accordingly to mimic $\mathrm{TM} 1 \mathrm{VO}_{2}$ values at the respective stages. This was done to ensure $\mathrm{VO}_{2}$ was equal across treadmill and cycle exercise for the respective stages.

\section{Statistical Analyses}

Two-way ANOVAs with a Bonferroni correction were used to determine main effects for trial and intensity within an exercise mode. For across mode analysis, a twoway ANOVA with Bonferroni correction was used to determine main effects for mode and intensity for the averages of the TM trials and the averages of the CYC trials. Intraclass correlation coefficients (ICC) determined the agreement within and across exercise modes at the absolute submaximal intensities. Coefficients of variation (CV) were used to determine the variability within and across exercise trials. Statistical significance was set a priori at $\mathrm{p}<0.05$.

\section{Results}

Subjects characteristics are listed in Table 2. Hemodynamic averages are displayed in Tables 3 and 4 for primary and secondary variables, respectively. For the treadmill, there were no main effects for trial for hemodynamic variables, with the exception of HR. For cycle exercise, there were no main effects for trial for any hemodynamic variable.

Within treadmill exercise, ICC for primary and secondary hemodynamic variables displayed reliability coefficients of $r \geq 0.7$ at both intensities indicating good agreement. 
For MODex and VIGex, CVs ranged from 3.4-8.7\% and 3.1-10.5\%, respectively. Within MODex of cycle, all correlation coefficients achieved $r \geq 0.7$, indicating strong agreement, with the exception of SVR $(r=0.68)$ and CTi $(r=0.47)$ with CVs ranging from $2.3-12.1 \%$. For VIGex cycling, all hemodynamic variables had correlation coefficients $r<0.7$, except for $\mathrm{VO}_{2}(\mathrm{r}=0.93)$ and $\mathrm{HR}(\mathrm{r}=0.85)$ indicating good agreement for the two primary variables. For VIGex cycling, CVs ranged from 3.5-15.1\%.

For across mode analyses, the average values of TM1 and TM2 were compared to the averages of CYC1 and CYC2. Across treadmill and cycle exercise, there was an interaction effect for trial by intensity for CTi but not for other variables. There were no main effects for trial for any hemodynamic variable, with the exception of greater HR in cycling and greater SV and EDV in treadmill exercise.

Across treadmill and cycle exercise all primary and secondary variables during MODex had reliability coefficients $\mathrm{r} \geq 0.7$. For VIGex, CO, HR, SV, EDV, EF, and CTi exhibited reliability coefficients $r \geq 0.7$, indicating strong agreement. However, SVR and LCWi achieved reliability coefficients of $\mathrm{r}<0.7$ showing a lack of agreement across treadmill and cycle exercise. CVs ranged from 2.7-9.3\% and 2.1-10.5\% for MODex and VIGex, respectively across exercise modes.

\section{Discussion}

The purpose of this study was to determine the physiological differences across treadmill and cycle exercise utilizing PhysioFlow ICG at moderate and vigorous exercise intensities. The present study found strong agreement within treadmill exercise and moderate cycle exercise. Furthermore, PhysioFlow ICG showed strong agreement for the 
majority of primary and secondary hemodynamic variables for both intensities when comparing across treadmill and cycle exercise.

The current study is the first to examine the reliability of PhysioFlow ICG within treadmill exercise. For MODex and VIGex intensities, all primary and secondary hemodynamic variables were in strong agreement. There were no main effects for trials within treadmill exercise with the exception of HR. For a given stage, HR decreased by 4 bpm from TM1 to TM2. Sime et. al. discovered that HR statistically decreased in subsequent testing in about one-third of subjects with one week of separation between trials possibly due to task and setting familiarity (Sime et al., 1972). As there was no familiarization trial performed in the current study, this phenomenon could have occurred as TM1 was designated as the first visit.

Previous literature has investigated the PhysioFlow ICG's reproducibility in cycle exercise. Schultz et. al. determined the reliability during submaximal cycle exercise at $70 \%$ of age predicted max heart rate (APMHR) during a 5-minute steady state bout (Schultz et al., 2012). Hemodynamic data was recorded for 5 minutes once steady state was achieved at the given workload. Schultz observed all ICC's for hemodynamic variables achieving $r$ $\geq 0.7$ during all exercise stages. Schultz's $70 \%$ APMHR best corresponds with the current study's MODex as both are considered moderate intensities (American College of Sports Medicine, 2013). The present study's MODex showed similar results to Schultz et. al. 70\% APMHR with all ICC achieve $r \geq 0.7$, with the exception of SVR $(r=0.68)$ and CTi (0.47). The lack of agreement in SVR is uncertain due to no statistical differences in systolic and diastolic blood pressure (SBP and DBP). However, the lack of agreement in CTi may be attributed to poor signal quality leading to device error. There were two outliers outside 
two standard deviations in MODex CTi for CYC1, and when omitted from the cycle ICC analysis, $\mathrm{r}=0.91(\mathrm{p}<0.001)$.

VIGex of the current study was designated to be a vigorous submaximal intensity at an absolute workload. In contrast to treadmill exercise, cycle exercise correlation coefficients in VIGex were $r<0.7$ for all variables except for HR. The low correlations may be attributed to the vigorous nature of the steady-state stage in an unfamiliar exercise mode, as most subjects were not cycle trained. This could have resulted in a different physiological response in the higher intensity stage from CYC1 to CYC2. Respiratory exchange ratio (RER) was significantly higher in cycle exercise compared to treadmill at the vigorous intensity $(0.94 \pm 0.07$ versus $0.87 \pm 0.04, \mathrm{p}<0.001)$. The difference in RER suggests that VIGex cycling was relatively more difficult compared to treadmill exercise at the same $\mathrm{VO}_{2}$. In a previous study where subjects performed maximal treadmill and cycling tests, RER was significantly higher in cycling at 150 and $170 \mathrm{bpm}$ (McArdle and Magel, 1970). Furthermore, percent $\mathrm{VO}_{2}$ max was significantly higher at 150 and $170 \mathrm{bpm}$ in cycling compared to treadmill suggesting cycle exercise was more demanding at a given heart rate.

When comparing across modes, SV significantly increased in treadmill exercise possibly due to a greater EDV allowing for a more efficient contraction via the FrankStarling mechanism. Contrarily in cycle exercise, there was no change in SV, EDV, EF, and CTi with an increase in intensity. SV traditionally plateaus at $40 \% \mathrm{VO}_{2}$ max (Vella and Robergs, 2005). MODex $\mathrm{VO}_{2}$ was calculated to be $45 \%$ of cycling $\mathrm{VO}_{2}$ max for both cycle trials suggesting the plateau in SV may result from no change in EDV, CTi, and EF in cycle exercise. To compensate for the statistically lower SV $(p=0.01)$, cycling HR was 
measured to be statistically higher $(\mathrm{p}=0.01)$ to create an equal $\mathrm{CO}$ at the given $\mathrm{VO}_{2}$ across exercise modes. Similar results were found previously while using the gold-standard, dye dilution (Hermansen, Ekblom and Saltin, 1970). During MODex and VIGex, cycling HR averaged to be 4 and $6 \mathrm{bpm}$ higher compared to treadmill for the given stage. These values were at the lower end of Hermansen's 6-10 bpm difference between cycle and treadmill exercise. Hermansen attributed the difference in hemodynamics due to increased pressure in cycling that may impede blood flow to the muscle.

In the present study, mean arterial pressure (MAP) was not statistically different across exercise modes at a given intensity; however, this is due to statistically higher SBP (MODex SBP: $140 \pm 11$ versus $146 \pm 14 \mathrm{mmHg}$, $\mathrm{p}=0.001$; VIGex SBP: $158 \pm 3$ versus 169 $\pm 4 \mathrm{mmHg}, \mathrm{p}=0.002$ ) and statistically lower DBP (MODex DBP: $67 \pm 8$ versus $60 \pm 6$ $\mathrm{mmHg}, \mathrm{p}=0.001$; VIGex DBP: $64 \pm 1$ versus $56 \pm 1 \mathrm{mmHg}, \mathrm{p}=0.002$ ) in cycling compared to treadmill. The higher SBP in cycle exercise can be attributed to prolonged isometric contractions and vessel compression as a result of pedaling mechanics versus running (Palatini, 1988). The vessel compression during cycling reduces the compliance of the arteries causing a greater decrease in DBP (London and Guerin, 1999). As a result, HR may be increased at a given $\mathrm{VO}_{2}$ to maintain adequate blood flow with the increased vessel compression during cycling.

There are some physiological mechanisms that may explain the lack of agreement across exercise modes. Previous literature has reported SVR as the product of MAP and mean right atrial pressure (MRAP) divided by CO (Stamler et al., 1994). There were no significant differences in MAP or CO across modes during VIGex. Therefore, the lack of agreement in SVR may be associated with differences in MRAP. However, MRAP was 
not measured in the current study, so this cannot be concluded with certainty. Although MAP was not statistically different during VIGex, the lack of agreement may extend from the observed differences in SBP and DBP across exercise modes.

Similarly, LCWi is calculated as the difference between MAP and left ventricular end diastolic pressure (LVEDP) multiplied by cardiac index (CI), which is CO accounted for body surface area (Ferguson, Gregg and Shadle, 1954). The lack of agreement across exercise modes could also be attributed to the observed differences in SBP and DBP. Moreover, with EDV statistically greater in treadmill exercise, the LVEDP would have been greater compared to cycling suggesting that the differences in pressure may lead to the lack of agreement in VIGex LCWi across modes (Burkhoff, Mirsky and Suga, 2005).

Lastly, there was a significant mode by intensity interaction effect for CTi across exercise modes with a trending main effect for intensity $(\mathrm{p}=0.07)$. CTi is known as the heart's inherent ability to produce force in relation to an individual's body surface area, independent of changes in preload and afterload (Bombardini, 2005). However, in a recent review by Bombardini discussing myocardial contractility, it is suggested that greater force will be produced with an increase in sarcomere length at a given calcium ion concentration (Bombardini, 2005). In treadmill exercise, there may be increased sarcomere length due to greater EDV as intensity increases. As a result, contractility may be increasing more in treadmill exercise compared to cycle as intensity increases.

\section{Limitations}

The sample of subjects in this study was not completely random as subjects were college-aged males recruited through word-of-mouth recruiting and bulk-email requests advertising the need for subjects. However, this can be viewed as a strength of the current 
study as using a homogeneous population would likely reduce the hemodynamic variable ICCs.

The present study cannot validate PhysioFlow ICG due to lack of access to direct measurements, so the present study must rely on previous research to validate the device (Charloux et al., 2000; Richard et al., 2001; Robach et al., 2008). It is important to note that lack of agreement may reflect physiological differences across exercise modes, as well as day-to-day variation in hemodynamics with the remainder of variability associated with the device.

Future research may wish to investigate PhysioFlow ICG measures in subjects who are trained in running and cycling exercise, such as duathlon participants or triathletes. This may establish better agreement across modes or in VIGex of cycling. Experimenting across broader range of exercise modes would be beneficial to determine if different postural positions effect hemodynamics during exercise. Furthermore, future research may wish to utilize invasive methods to validate the hemodynamic differences observed between TM and CYC.

\section{Conclusions}

Across treadmill and cycle exercise, the PhysioFlow ICG showed higher HR with lower $\mathrm{SV}$ and $\mathrm{EDV}$ in cycling exercise for a given $\mathrm{VO}_{2}$, which is in accordance with previous literature using a gold standard technique. Correlation coefficients were strong across exercise mode during MODex for all hemodynamic variables. For VIGex, all hemodynamic variables were strong with the exception of SVR and LWCi. However, the lack of agreement may be explained by the physiological differences observed across exercise mode. Finally, device error should be associated with the lack in agreement after 
day-to-day variation in hemodynamics and physiological differences across exercise modes are taken into consideration. 


\section{Manuscript References}

American College of Sports Medicine (2013) ACSM's guidelines for exercise testing and prescription. 9th editio. Lippincott Williams \& Wilkins.

American College of Sports Medicine and Ehrman, J. K. (2014) ACSM's Resource Manual for Guidelines for Exercise Testing and Prescription. 7th edn. Philadelphia: Lippincott Williams \& Williams.

Bernstein, D. P. (1986) 'A new stroke volume equation for thoracic electrical bioimpedance: theory and rationale.', Critical care medicine, 14(10), pp. 904-9.

Available at: http://www.ncbi.nlm.nih.gov/pubmed/3757533 (Accessed: 6 February 2016).

Bombardini, T. (2005) 'Myocardial contractility in the echo lab : molecular, cellular and pathophysiological basis', Cardiovascular Ultrasound, 3(27), pp. 1-22. doi:

10.1186/1476-7120-3-27.

Burkhoff, D., Mirsky, I. and Suga, H. (2005) 'Assessment of systolic and diastolic ventricular properties via pressure- volume analysis: a guide for clinical, translational, and basic researchers', The American Journal of Physiology: Heart and Circulatory Physiology, 289(2), pp. H501-H512. Available at:

http://ajpheart.physiology.org/content/ajpheart/289/2/H501.full.pdf (Accessed: 27 March 2017).

Chapman, A. B., Zamudio, S., Woodmansee, W., Merouani, A., Osorio, F., Johnson, A., Moore, L. G., Dahms, T., Coffin, C., Abraham, W. T. and Schrier, R. W. (1997) 'Systemic and renal hemodynamic changes in the luteal phase of the menstrual cycle mimic early pregnancy.', The American journal of physiology, 273(5 Pt 2), pp. F777-82. Available at: http://www.ncbi.nlm.nih.gov/pubmed/9374841.

Charloux, A., Lonsdorfer-Wolf, E., Richard, R., Lampert, E., Oswald-Mammosser, M., Mettauer, B., Geny, B. and Lonsdorfer, J. (2000) 'A new impedance cardiograph device for the non-invasive evaluation of cardiac output at rest and during exercise: comparison with the "direct" Fick method', European Journal of Applied Physiology, 82(4), pp. 313320. doi: 10.1007/s004210000226.

Faulkner, J. a, Roberts, D. E., Elk, R. L. and Conway, J. (1971) 'Cardiovascular responses to submaximum and maximum effort cycling and running.', Journal of applied physiology (Bethesda, Md. : 1985), 30(4), pp. 457-461.

Ferguson, T. B., Gregg, D. E. and Shadle, O. W. (1954) 'Effect of Blood and Saline Infusion on Cardiac Performance in Normal Dogs and Dogs with Arteriovenous Fistulas', Circulation Research, 11, pp. 565-572.

Gledhill, N., Cox, D. and Jamnik, R. (1994) 'Endurance athletes' stroke volume does not 
plateau: major advantage is diastolic function.', Medicine and science in sports and exercise, 26(9), pp. 1116-21. Available at:

http://www.ncbi.nlm.nih.gov/pubmed/7808245 (Accessed: 9 November 2016).

Hermansen, L., Ekblom, B. and Saltin, B. (1970) 'Cardiac output during submaximal and maximal treadmill and bicycle exercise.', Journal of applied physiology, 29(1), pp. 82-6. Available at: http://www.ncbi.nlm.nih.gov/pubmed/4912876.

Kubicek, W. G., Karnegis, J. N., Patterson, R. P., Witsoe, D. A. and Mattson, R. H. (1966) 'Development and evaluation of an impedance cardiac output system.', Aerospace medicine, 37(12), pp. 1208-12. Available at:

http://www.ncbi.nlm.nih.gov/pubmed/5339656 (Accessed: 9 February 2016).

London, G. M. and Guerin, A. P. (1999) 'Influence of arterial pulse and reflected waves on blood pressure and cardiac function', American Heart Journal, 138(3), pp. S220S224. doi: 10.1016/S0002-8703(99)70313-3.

McArdle, W. D. and Magel, J. R. (1970) 'Physical work capacity and maximum oxygen uptake in treadmill and bicycle exercise.', Medicine and science in sports. Nyboer, J., Kreider, M. M. and Hannapel, L. (1950) 'Electrical impedance plethysmography; a physical and physiologic approach to peripheral vascular study.', Circulation, 2(6), pp. 811-821. doi: 10.1161/01.CIR.2.6.811.

Palatini, P. (1988) 'Blood Pressure Behaviour During Physical Activity', Sports Medicine: An International Journal of Applied Medicine and Science in Sport and Exercise, 5(6), pp. 353-374. doi: 10.2165/00007256-198805060-00002.

Richard, R., Lonsdorfer-Wolf, E., Charloux, a., Doutreleau, S., Buchheit, M., OswaldMammosser, M., Lampert, E., Mettauer, B., Geny, B. and Lonsdorfer, J. (2001) 'Noninvasive cardiac output evaluation during a maximal progressive exercise test, using a new impedance cardiograph device', European Journal of Applied Physiology, 85(3-4), pp. 202-207. doi: 10.1007/s004210100458.

Robach, P., Calbet, J. A. L., Thomsen, J. J., Boushel, R., Mollard, P., Rasmussen, P. and Lundby, C. (2008) 'The ergogenic effect of recombinant human erythropoietin on VO2max depends on the severity of arterial hypoxemia.', PloS one. Public Library of Science, 3(8), p. e2996. doi: 10.1371/journal.pone.0002996.

Schultz, M. G., Climie, R. E. D., Nikolic, S. B., Ahuja, K. D. and Sharman, J. E. (2012) 'Reproducibility of cardiac output derived by impedance cardiography during postural changes and exercise', Artery Research. Elsevier B.V, 6(2), pp. 78-84. doi: 10.1016/j.artres.2012.02.001.

Sime, W. E., Whipple, I. T., Berkson, D. M., MacIntyre, W. C. and Stamler, J. (1972) 'Reproducibility of heart rate at rest and in response to submaximal treadmill and bicycle ergometer test in middle-aged men', Medicine \& Science in Sports \& Exercise, 4(1), pp. 
$14-17$.

Sramek, B. B. (1982) 'Cardiac output by electrical impedance.', Medical electronics, 13(2), pp. 93-7. Available at: http://www.ncbi.nlm.nih.gov/pubmed/10257596 (Accessed: 9 February 2016).

Stamler, J. S., Loh, E., Roddy, M. A., Currie, K. E. and Creager, M. A. (1994) 'Nitric oxide regulates basal systemic and pulmonary vascular resistance in healthy humans.', Circulation, 89(5), pp. 2035-40. doi: 10.1161/01.CIR.89.5.2035.

Vella, C. A. and Robergs, R. A. (2005) 'A review of the stroke volume response to upright exercise in healthy subjects', British Journal of Sports Medicine , 39(4), pp. 190195. doi: 10.1136/bjsm.2004.013037.

Warburton, D. E. R., Haykowsky, M. J. F., Quinney, H. A., Humen, D. P. and Teo, K. K. (1999) 'Reliability and Validity of Measures of Cardiac Output During Incremental to Maximal Aerobic Exercise', Sports Medicine, 27(4), pp. 241-260. doi:

10.2165/00007256-199927040-00004. 
Table 1 Treadmill and Cycling Protocols

$\begin{array}{lccc}\text { Time } & \text { TM Speed (mph) } & \text { TM Grade }(\%) & \text { Cycle METs } \\ \text { 0:01 - 0:59 } & 2.6 & 0 & 2 \\ \text { 1:00 - 1:59 } & 3.1 & 1.5 & 3.4 \\ \text { 2:00 - 6:59* } & 3.6 & 2.5 & 5 \\ \text { 7:00 -7:59 } & 4 & 3.5 & 6.4 \\ \text { 8:00 - 12:59* } & 4 & 5.5 & 7 \\ \text { 13:00-13:59 } & 4.6 & 0 & 8.4 \\ \text { 14:00-14:59 } & 5 & 1 & 9.8 \\ \text { 15:00-15:59 } & 5.3 & 2.5 & 11.2 \\ \text { 16:00-16:59 } & 5.6 & 5 & 12.6 \\ \text { 17:00 - 17:59 } & 6.1 & 6.5 & 14 \\ \text { 18:00 - 18:59 } & 6 & 10.5 & 15.4 \\ \text { 19:00-19:59 } & 6 & 14 & 16.8 \\ \text { 20:00-20:59 } & 6 & 16.5 & 18.2 \\ \text { 21:00-21:59 } & 6.2 & 17.5 & 19.6 \\ \text { 22:00-22:59 } & 6.4 & 18.5 & 21\end{array}$

*Data collected in final two minutes of the given stage was used for analyses. 
Table 2 Subject Characteristics $(n=21)$

\begin{tabular}{lc}
\hline Age (years) & $21.4 \pm 0.5$ \\
IPAQ $\left(\mathrm{MET} \cdot \mathrm{min} \cdot \mathrm{week}^{-1}\right)$ & $4825.7 \pm 801.1$ \\
Height $(\mathrm{cm})$ & $178.9 \pm 2.0$ \\
Weight $(\mathrm{kg})$ & $73.2 \pm 2.7$ \\
$\mathrm{BMI}\left(\mathrm{kg} / \mathrm{m}^{2}\right)$ & $24.5 \pm 0.5$ \\
$\mathrm{VO}_{2} \mathrm{max}\left(\mathrm{mL} \cdot \mathrm{kg}^{-1} \cdot \mathrm{min}^{-1}\right)$ & $51.5 \pm 1.5$ \\
\hline
\end{tabular}

Mean ( \pm SD) cm: IPAQ: International Physical Activity Questionnaire. MET: metabolic equivalent of task. BMI: body mass index. $\mathrm{VO}_{2}$ max: maximal oxygen consumption. 
Table 3 Mean Values of Primary Hemodynamic Variables for Treadmill and Cycle exercise at moderate and vigorous intensity.

\begin{tabular}{lcc} 
& Averaged TM & Averaged CYC \\
\hline $\begin{array}{l}\text { MODex VO } \\
\left(\mathrm{mL} \cdot \mathrm{min}^{-1}\right)\end{array}$ & $1571.5 \pm 253.6$ & $1565.0 \pm 260.4$ \\
$\begin{array}{l}\text { VIGex VO} \\
\left(\mathrm{mL} \cdot \mathrm{min}^{-1}\right)\end{array}$ & $2248.6 \pm 391.9 \dagger$ & $2326.2 \pm 432.8 \dagger$ \\
$\begin{array}{l}\text { MODex CO } \\
\left(\mathrm{L} \cdot \mathrm{min}^{-1}\right)\end{array}$ & $14.3 \pm 1.9$ & $14.2 \pm 2.9$ \\
$\begin{array}{l}\text { VIGex CO } \\
\left(\mathrm{L} \cdot \mathrm{min}^{-1}\right)\end{array}$ & $19.6 \pm 2.9 \dagger$ & $18.8 \pm 2.6 \dagger$ \\
$\begin{array}{l}\text { MODex HR } \\
\left(\mathrm{beats} \cdot \mathrm{min}^{-1}\right)\end{array}$ & $114 \pm 11$ & $118 \pm 13$ \\
$\begin{array}{l}\text { VIGex HR* } \\
(\text { beats·min }\end{array}$ & $145 \pm 14 \dagger$ \\
$\begin{array}{l}\text { MODex SV } \\
\left(\mathrm{mL} \cdot \mathrm{beat}^{-1}\right)\end{array}$ & $126.5 \pm 16.8$ & $151 \pm 17 \dagger$ \\
$\begin{array}{l}\text { VIGex SV } \\
\left(\mathrm{mL} \cdot \mathrm{beat}^{-1}\right)\end{array}$ & $134.5 \pm 18.0 \dagger$ & $121.3 \pm 22.1$ \\
\hline
\end{tabular}

Mean $( \pm \mathrm{SD}) . *$ indicates a significant $(\mathrm{p}<0.05)$ main effect for mode of across treadmill $(\mathrm{TM})$ and cycle $(\mathrm{CYC})$ exercise. $\dagger$ indicates significant $(\mathrm{p}<0.05)$ main effect for intensity within a mode. MODex: moderate exercise. VIGex: vigorous exercise. $\mathrm{VO}_{2}$ : oxygen consumption. $\mathrm{CO}$ : cardiac output. HR: heart rate. SV: stroke volume. 
Table 4 Mean Values of Secondary Hemodynamic Variables for Treadmill and Cycle exercise at moderate and vigorous intensity.

Averaged TM Averaged CYC

\begin{tabular}{|c|c|c|}
\hline $\begin{array}{l}\text { MODex EDV } \\
(\mathrm{mL})\end{array}$ & $155.2 \pm 23.7$ & $145.7 \pm 26.8$ \\
\hline $\begin{array}{l}\text { VIGex EDV* } \\
(\mathrm{mL})\end{array}$ & $161.8 \pm 25.2 \dagger$ & $150.4 \pm 25.4$ \\
\hline $\begin{array}{l}\text { MODex EF } \\
(\%)\end{array}$ & $82.3 \pm 5.2$ & $83.6 \pm 6.4$ \\
\hline $\begin{array}{l}\text { VIGex EF } \\
(\%)\end{array}$ & $83.8 \pm 6.8$ & $83.4 \pm 7.1$ \\
\hline $\begin{array}{l}\text { MODex SVR } \\
\left(\text { dyn } \cdot s \cdot \mathrm{cm}^{-5}\right)\end{array}$ & $516.1 \pm 73.8$ & $503.7 \pm 72.7$ \\
\hline $\begin{array}{l}\text { VIGex SVR } \\
\left(\text { dyn } \cdot s \cdot \mathrm{cm}^{-5}\right)\end{array}$ & $396.8 \pm 66.6 \dagger$ & $400.0 \pm 53.1 \dagger$ \\
\hline MODex CTi & $350.7 \pm 67.9$ & $369.0 \pm 98.3$ \\
\hline VIGex CTi & $400.4 \pm 88.6 \dagger$ & $369.2 \pm 84.3$ \\
\hline $\begin{array}{l}\text { MODex LCWi } \\
\left(\mathrm{kg} \cdot \mathrm{m} \cdot \mathrm{m}^{2 \cdot-1}\right)\end{array}$ & $9.1 \pm 1.3$ & $8.7 \pm 2.0$ \\
\hline $\begin{array}{l}\text { VIGex LCWi } \\
\left(\mathrm{kg} \cdot \mathrm{m} \cdot \mathrm{m}^{2-1}\right)\end{array}$ & $12.9 \pm 2.0 \dagger$ & $12.0 \pm 1.8 \dagger$ \\
\hline
\end{tabular}

Mean $( \pm \mathrm{SD}) . *$ indicates a significant $(\mathrm{p}<0.05)$ main effect for mode of across treadmill $(\mathrm{TM})$ and cycle $(\mathrm{CYC})$ exercise. $\dagger$ indicates significant $(\mathrm{p}<0.05)$ main effect for intensity within a mode. MODex: moderate exercise. VIGex: vigorous exercise. EDV: end diastolic volume. EF: ejection fraction. SVR: systemic vascular resistance. CTi: contractility index. LCWi: left cardiac work index. 


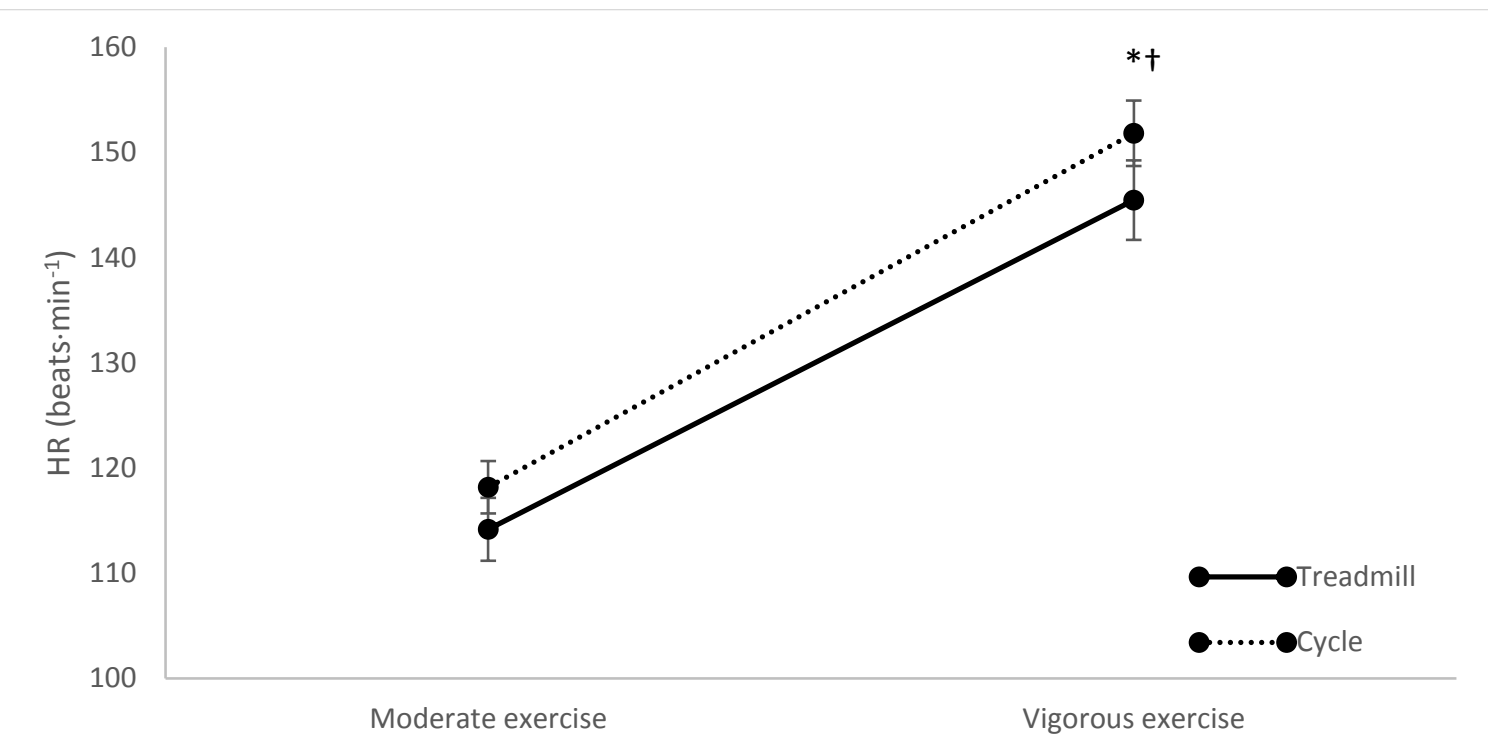

Figure 1 Heart rate response from moderate to vigorous exercise across treadmill and cycle exercise. * indicating significant $(\mathrm{p}<0.05)$ main effect for mode. + indicating significant $(\mathrm{p}<0.05)$ main effect for intensity. 


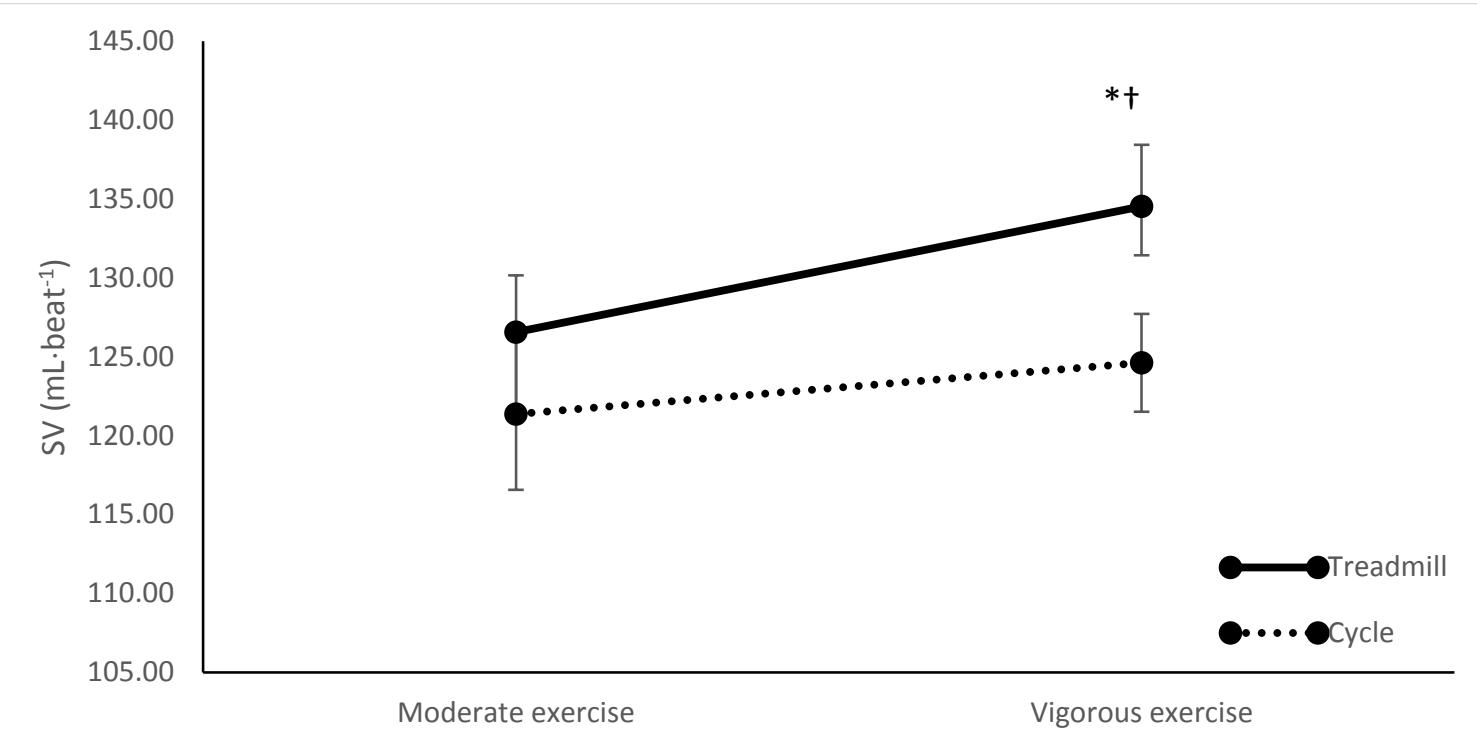

Figure 2 Stroke Volume response from moderate to vigorous exercise across treadmill and cycle exercise. $*$ indicating significant $(\mathrm{p}<0.05)$ main effect for mode. + indicating significant $(\mathrm{p}<0.05)$ main effect for intensity. 


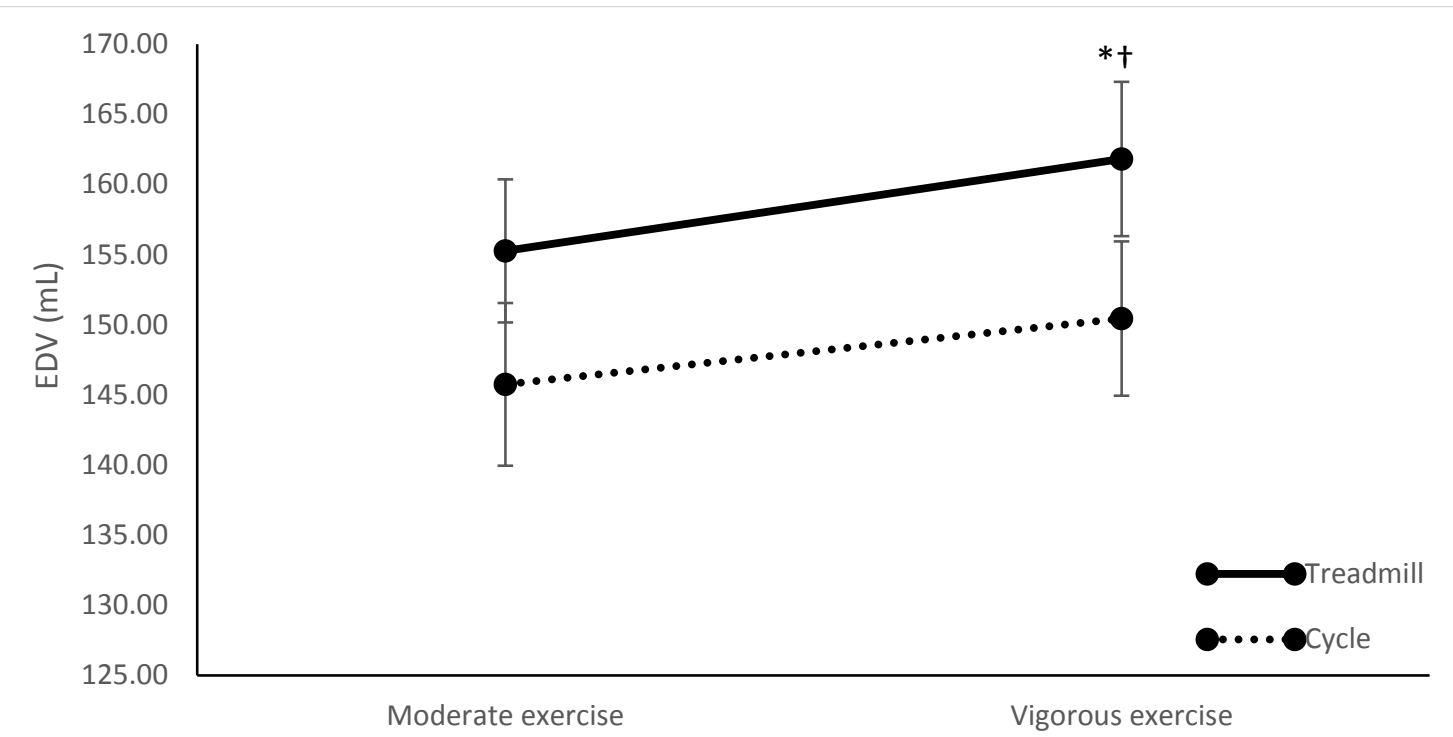

Figure 3 End Diastolic Volume response from moderate to vigorous exercise across treadmill and cycle exercise. $*$ indicating significant $(\mathrm{p}<0.05)$ main effect for mode. $†$ indicating significant $(\mathrm{p}<0.05)$ main effect for intensity. 


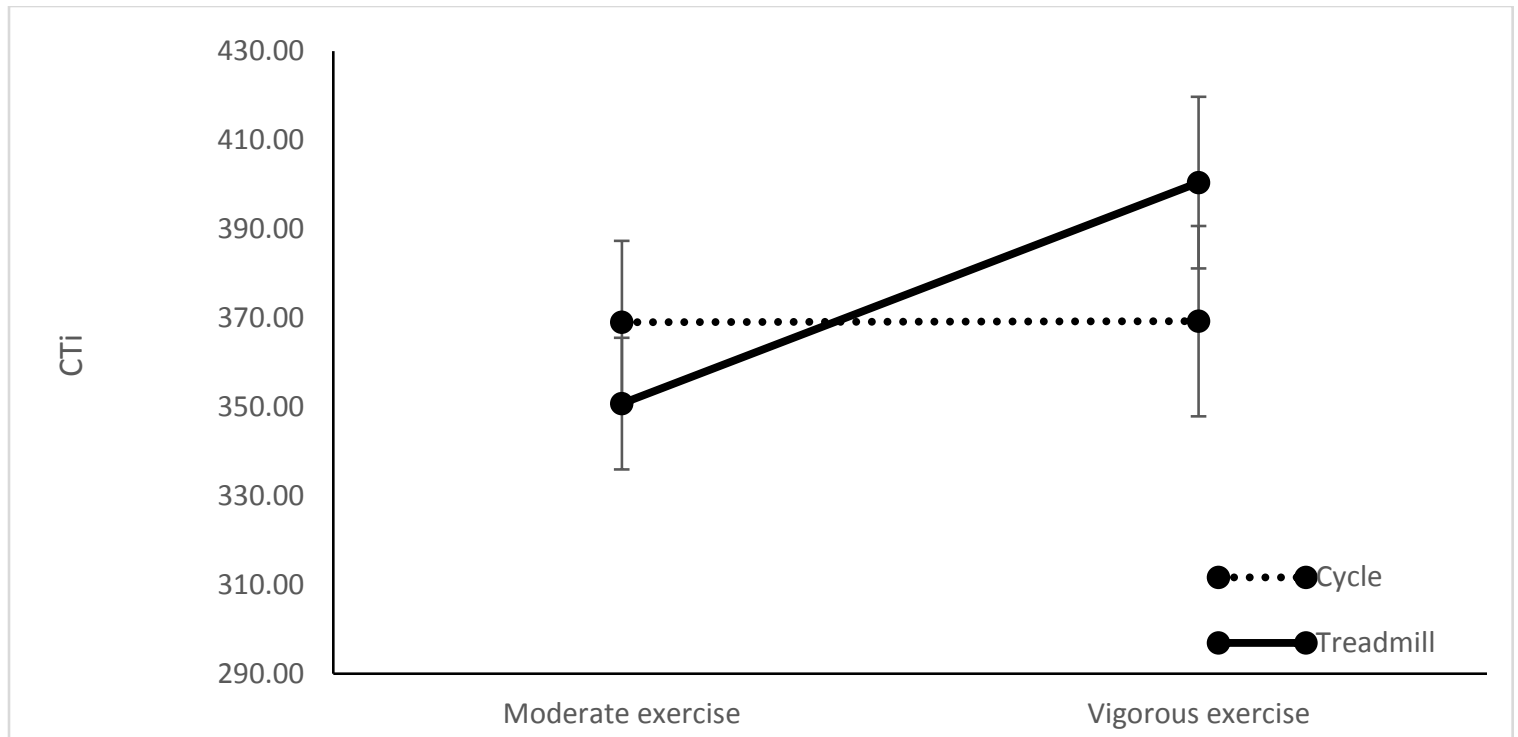

Figure 4 Contractility Index response from moderate to vigorous exercise across treadmill and cycle exercise. * indicating significant $(\mathrm{p}<0.05)$ main effect for mode. + indicating significant $(\mathrm{p}<0.05)$ main effect for intensity. 


\title{
Appendices
}

\author{
James Madison University \\ Department of Kinesiology \\ Informed Consent
}

\section{Purpose}

You are being asked to volunteer for a research study conducted by Dr. Trent Hargens from James Madison University entitled, "Reliability of Impedance Cardiography in the Measurement of Cardiovascular Hemodynamics During Exercise".

The goal of this study is to examine whether a method for non-invasively measuring cardiovascular measures is repeatable on multiple days and on multiple exercise modes.

\section{Experimental Procedures}

You will be asked to visit the Human Performance Laboratory (HPL) in Godwin Hall 4 times over the course of about $2-4$ weeks. Your total time commitment for participation in this study will be about 4 hours (each visit about an hour).

Upon completion of this informed consent, you will be asked to complete 2 short questionnaires, 1 that asks about your ability to participate in physical activity, and 1 that asks about your current level of physical activity participation. Each of these questionnaires should take about 5 minutes to complete.

You will then have your height and weight measured. Upon completion of this, you will be asked to complete a maximal treadmill exercise test. During the test, researchers will monitor your heart rate, blood pressure and your perceived exertion to the workload you will be doing. You will have several electrode patches placed on your skin on your torso, back and neck. These will be connected to the device measuring the variables we are interested in studying. During the test, you will breathe only through a mouthpiece, with your nose clamped off, so that we can measure the amount of oxygen you use during exercise. The treadmill will start with a very slow speed and little grade, and will steadily increase in speed and grade throughout the test, so it will start easy, and become very intense. At the end of the test, it should be a best effort on your part. It may be as hard as any exercise you remember doing. The exercise test will last about 10 -15 minutes. Prior to your arrival to the HPL that day, you will be asked to refrain from eating for 4 hours prior to your arrival, and to avoid caffeine and alcohol for that time period as well.

Upon completion of this visit, you will be asked to return to the HPL 3 subsequent times, a minimum of 48 hours later, and at the same time of day as the first visit. The remaining 3 visits will consist of an additional maximal treadmill test, identical to your 
visit 1, or a maximal cycle exercise test. For the cycle test, you will be asked to pedal a cycle ergometer at a certain work rate that will steadily increase in difficulty until you are no longer able to maintain at least $50 \mathrm{rpm}$. It will start fairly easy, and become very intense, in a similar fashion to the treadmill. We will measure the same things during the cycle test as we do during the treadmill test. What type of test you complete (treadmill or cycle) for visits $2-4$ will be randomized.

\section{Risks}

There is a risk of abnormal changes during the maximal exercise tests. These changes may include abnormal blood pressure, fainting, heart rhythm disorders, stroke, heart attack, and death. The chance of serious heart problems during maximal exercise among adults is very small (less than $1 / 10,000$ maximal exercise tests). Every effort will be made to minimize risks of an abnormal response by reviewing you health history and providing adequate supervision of the exercise test. All staff are certified by the American Heart Association in BLS (Basic Life Support), and all tests will be supervised by individuals certified by the American College of Sports Medicine.

\section{Benefits}

Participation may include knowledge about your health status. You will receive information on your cardiovascular fitness.

\section{Inquiries}

If you have any questions or concerns or you would like to receive a copy of the final aggregate results of this study, please contact Dr. Trent Hargens at hargenta@jmu.edu or (540) 568-5844.

\section{Questions about Your Rights as a Research Subject \\ Dr. David Cockley \\ Chair, Institutional Review Board \\ James Madison University \\ (540) 568-2834 \\ cocklede@jmu.edu \\ Confidentiality}

All data and results will be kept confidential. You will be assigned an identification number and a pseudonym in place of your real name. At no time will your name be identified with your individual data. The researcher retains the right to use and publish non-identifiable data. All paper data will be kept secured in a locked cabinet in a locked office. All electronic data will be kept on a password-protected computer in encrypted 
file folders. Upon completion of the study, only de-identified data will be kept for research dissemination purposes, and will be kept indefinitely. All material containing identifiable information will be destroyed. Final aggregate results will be made available to participants upon request.

\section{Freedom of Consent}

Your participation is entirely voluntary. You are free to choose not to participate. Should you choose to participate, you can withdraw at any time without consequences of any kind.

I have read this consent form and I understand what is being requested of me as a participant in this study. I freely consent to participate. I have been given satisfactory answers to my questions. The investigator provided me with a copy of this form I requested it. I certify that I am at least 18 years of age. By clicking "Yes" to the question below and submitting this confidential online survey, I am consenting to participate in this research. 


\section{PAR-Q \& YOU}

(A questionnaire for People Aged 15-69)

Regular physical activity is fun and healthy, and increasingly more people are starting to become more active every day. Being more active is very safe for most people. However, some people should check with your doctor before you start.

If you are planning to become much more physically active than you are now, start by answering the seven questions in the box below. If you are between the ages of 15 and 69 , the PAR-Q will tell you if you should check with your doctor before you start. If you are over 69 years of age, and you are not used to being very active, check with your doctor.

Common sense is your best guide when you answer these questions. Please read the questions carefully and answer each one honestly: check YES or NO

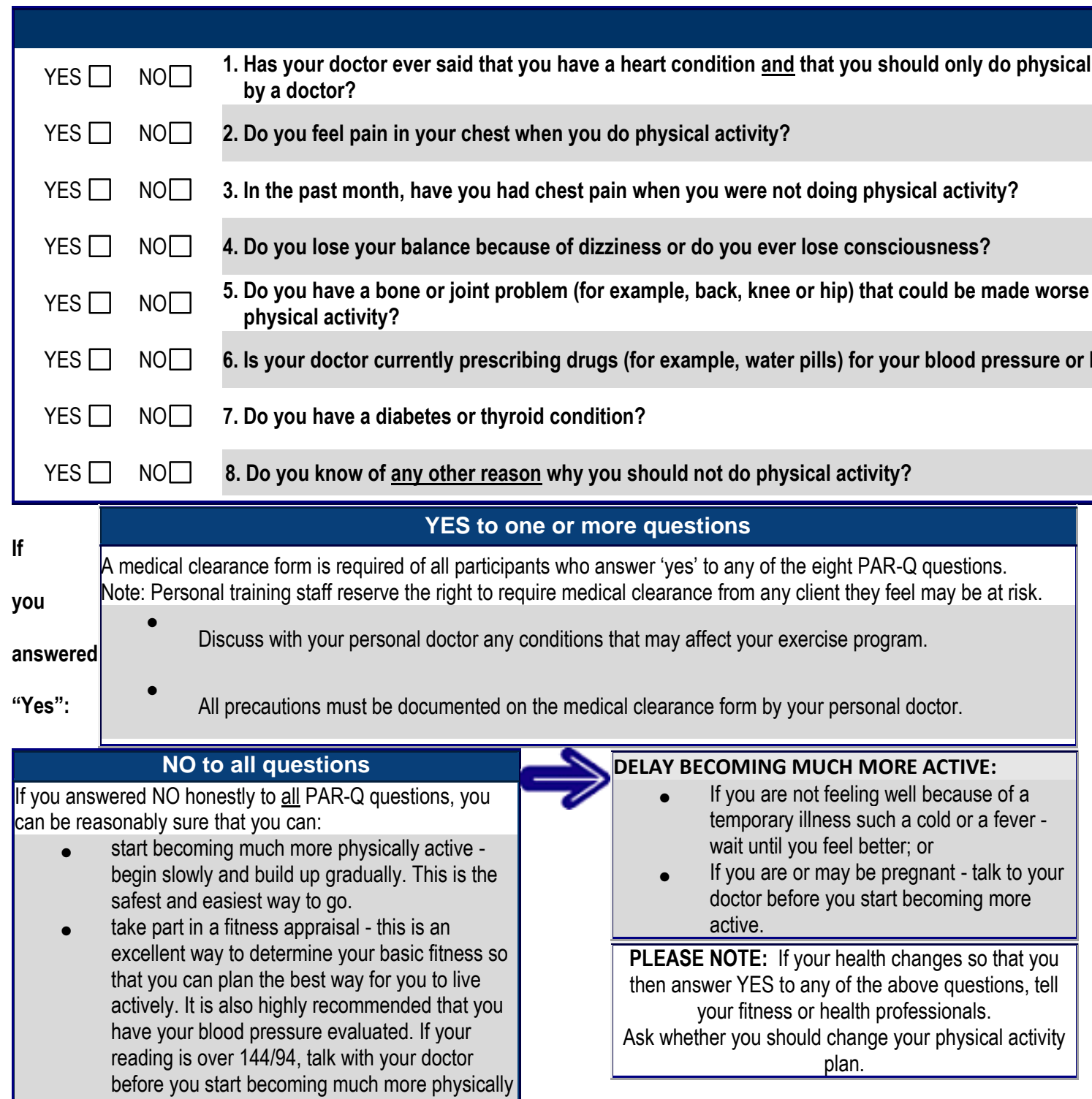

Informed Use of the PAR-Q: The Canadian Society for Exercise Physiology, Health Canada, and their agents assume no liability to persons who undertake physical activity, and if in doubt after completing this questionnaire, consult your doctor prior to physical activity.

NOTE: If the PAR-Q is being given to a person before he or she participates in a physical activity program or a fitness appraisal, this section may be used for legal or administrative purposes. 
"I have read, understood and completed this questionnaire. Any questions I had were answered to my full satisfaction."

NAME

SIGNATURE

DATE

SIGNATURE OF PARENT or GUARDIAN

WITNESS

Note: This physical activity clearance is valid for a maximum of 12 months from the date it is completed and becomes invalid if your condition changes so that you would answer YES to any

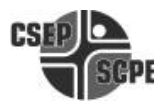
of the seven questions.

$\begin{array}{cll}\text { Supported by: } & \text { Health } & \text { Santé } \\ \text { Activity Readiness Questionnaire-PAR-Q } & \text { Canada } & \text { Canada }\end{array}$

Physical

by CW)

(revised 2006 


\section{INTERNATIONAL PHYSICAL ACTIVITY QUESTIONNAIRE}

We are interested in finding out about the kinds of physical activities that people do as part of their everyday lives. The questions will ask you about the time you spent being physically active in the last 7 days. Please answer each question even if you do not consider yourself to be an active person. Please think about the activities you do at work, as part of your house and yard work, to get from place to place, and in your spare time for recreation, exercise or sport.

Think about all the vigorous activities that you did in the last 7 days. Vigorous physical activities refer to activities that take hard physical effort and make you breathe much harder than normal. Think only about those physical activities that you did for at least 10 minutes at a time.

1. During the last $\mathbf{7}$ days, on how many days did you do vigorous physical activities like heavy lifting, digging, aerobics, or fast bicycling?

days per week

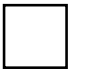

No vigorous physical activities

2. How much time did you usually spend doing vigorous physical activities on one of those days?

hours per day
minutes per day

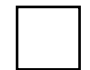

Don't know/Not sure

Think about all the moderate activities that you did in the last 7 days. Moderate activities refer to activities that take moderate physical effort and make you breathe somewhat harder than normal. Think only about those physical activities that you did for at least 10 minutes at a time.

3. During the last $\mathbf{7}$ days, on how many days did you do moderate physical activities like carrying light loads, bicycling at a regular pace, or doubles tennis? Do not include walking.

\section{days per week}

No moderate physical activities

Skip to question 5 
4. How much time did you usually spend doing moderate physical activities on one of those days?

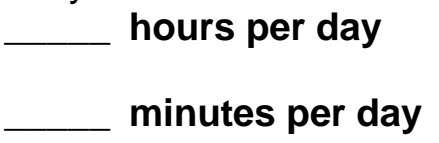

Don't know/Not sure

Think about the time you spent walking in the last $\mathbf{7}$ days. This includes at work and at home, walking to travel from place to place, and any other walking that you might do solely for recreation, sport, exercise, or leisure.

5. During the last $\mathbf{7}$ days, on how many days did you walk for at least $\mathbf{1 0}$ minutes at a time?

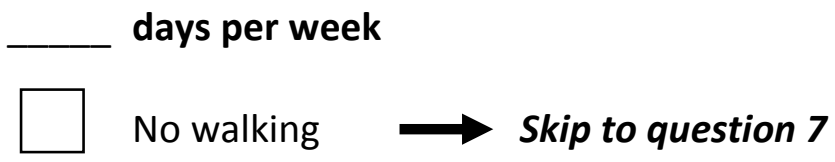

6. How much time did you usually spend walking on one of those days?

hours per day

minutes per day

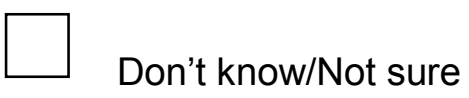

The last question is about the time you spent sitting on weekdays during the last 7 days. Include time spent at work, at home, while doing course work and during leisure time. This may include time spent sitting at a desk, visiting friends, reading, or sitting or lying down to watch television.

7. During the last $\mathbf{7}$ days, how much time did you spend sitting on a week day?

hours per day

minutes per day

$\square$ Don't know/Not sure 


\section{References}

American College of Sports Medicine (2013) ACSM's guidelines for exercise testing and prescription. 9th editio. Lippincott Williams \& Wilkins.

American College of Sports Medicine and Ehrman, J. K. (2014) ACSM's Resource Manual for Guidelines for Exercise Testing and Prescription. 7th edn. Philadelphia: Lippincott Williams \& Williams.

Bell, C., Monahan, K. D., Donato, A. J., Hunt, B. E., Seals, D. R. and Beck, K. C. (2003) 'Use of Acetylene Breathing to Determine Cardiac Output in Young and Older Adults Use of Acetylene Breathing to Determine Cardiac Output in Young', Med. Sci. Sports Exerc, 35(1), pp. 58-64. doi: 10.1249/01.MSS.0000043387.09154.53.

Bernstein, D. P. (1986) 'A new stroke volume equation for thoracic electrical bioimpedance: theory and rationale.', Critical care medicine, 14(10), pp. 904-9. Available at: http://www.ncbi.nlm.nih.gov/pubmed/3757533 (Accessed: 6 February 2016).

Bogui, P., Balayssac-Siransy, E., Connes, P., Tuo, N., Ouattara, S., Pichon, A. and Dah, C. S. (2013) 'The PhysioFlow Thoracic Impedancemeter Is Not Valid for the Measurements of Cardiac Hemodynamic Parameters in Chronic Anemic Patients', PLoS ONE, 8(10), pp. 1-10. doi: 10.1371/journal.pone.0079086.

Bougault, V. (2005) 'Does Thoracic Bioimpedance Accurately Determine Cardiac Output in COPD Patients During Maximal or Intermittent Exercise?\&lt;xref rid=“AFF1"\&gt;\&lt;sup\&gt;*\&lt;/sup\&gt;\&lt;/xref\&gt;', CHEST Journal, 127(4), p. 1122. doi: 10.1378/chest.127.4.1122.

Chapman, A. B., Zamudio, S., Woodmansee, W., Merouani, A., Osorio, F., Johnson, A., Moore, L. G., Dahms, T., Coffin, C., Abraham, W. T. and Schrier, R. W. (1997) 'Systemic and renal hemodynamic changes in the luteal phase of the menstrual cycle mimic early pregnancy.', The American journal of physiology, 273(5 Pt 2), pp. F777-82. Available at: http://www.ncbi.nlm.nih.gov/pubmed/9374841.

Charloux, A., Lonsdorfer-Wolf, E., Richard, R., Lampert, E., Oswald-Mammosser, M., Mettauer, B., Geny, B. and Lonsdorfer, J. (2000) 'A new impedance cardiograph device for the non-invasive evaluation of cardiac output at rest and during exercise: comparison with the "direct" Fick method', European Journal of Applied Physiology, 82(4), pp. 313320. doi: 10.1007/s004210000226.

Cournand, A., Riley, R. L., Breed, E. S., Baldwin, E. D., Richards, D. W., Lester, M. S. and Jones, M. (1945) 'MEASUREMENT OF CARDIAC OUTPUT IN MAN USING THE TECHNIQUE OF CATHETERIZATION OF THE RIGHT AURICLE OR VENTRICLE', Journal of Clinical Investigation, 24(1), pp. 106-116. doi: 10.1172/JCI101570. 
Ekblom, B., Åstrand, P. O., Saltin, B., Stenberg, J. and Wallström, B. (1968) 'Effect of training on circulatory response to exercise.', Journal of applied physiology (Bethesda, Md. : 1985), 24(4), pp. 518-528.

Faulkner, J. a, Roberts, D. E., Elk, R. L. and Conway, J. (1971) 'Cardiovascular responses to submaximum and maximum effort cycling and running.', Journal of applied physiology (Bethesda, Md. : 1985), 30(4), pp. 457-461.

Ferreira, E. M., Ota-Arakaki, J. S., B. Barbosa, P., Siqueira, A. C. B., Bravo, D. M., Kapins, C. E. B., Silva, C. M. C., Nery, L. E. and Alberto Neder, J. (2012) 'Signalmorphology impedance cardiography during incremental cardiopulmonary exercise testing in pulmonary arterial hypertension', Clinical Physiology and Functional Imaging, 32(5), pp. 343-352. doi: 10.1111/j.1475-097X.2012.01135.x.

Gledhill, N., Cox, D. and Jamnik, R. (1994) 'Endurance athletes' stroke volume does not plateau: major advantage is diastolic function.', Medicine and science in sports and exercise, 26(9), pp. 1116-21. Available at:

http://www.ncbi.nlm.nih.gov/pubmed/7808245 (Accessed: 9 November 2016).

Hermansen, L., Ekblom, B. and Saltin, B. (1970) 'Cardiac output during submaximal and maximal treadmill and bicycle exercise.', Journal of applied physiology, 29(1), pp. 82-6. Available at: http://www.ncbi.nlm.nih.gov/pubmed/4912876.

Howden, E. J., Perhonen, M., Peshock, R. M., Zhang, R., Arbab-Zadeh, A., Adams-Huet, B. and Levine, B. D. (2015) 'Females have a blunted cardiovascular response to 1-year of intensive supervised endurance training', Journal of Applied Physiology, 119, pp. 37-46. doi: 10.1152/japplphysiol.00092.2015.

Kubicek, W. G., Karnegis, J. N., Patterson, R. P., Witsoe, D. A. and Mattson, R. H. (1966) 'Development and evaluation of an impedance cardiac output system.', Aerospace medicine, 37(12), pp. 1208-12. Available at:

http://www.ncbi.nlm.nih.gov/pubmed/5339656 (Accessed: 9 February 2016).

McArdle, W. D. and Magel, J. R. (1970) 'Physical work capacity and maximum oxygen uptake in treadmill and bicycle exercise.', Medicine and science in sports. Nyboer, J., Kreider, M. M. and Hannapel, L. (1950) 'Electrical impedance plethysmography; a physical and physiologic approach to peripheral vascular study.', Circulation, 2(6), pp. 811-821. doi: 10.1161/01.CIR.2.6.811.

Richard, R., Lonsdorfer-Wolf, E., Charloux, a., Doutreleau, S., Buchheit, M., OswaldMammosser, M., Lampert, E., Mettauer, B., Geny, B. and Lonsdorfer, J. (2001) 'Noninvasive cardiac output evaluation during a maximal progressive exercise test, using a new impedance cardiograph device', European Journal of Applied Physiology, 85(3-4), pp. 202-207. doi: 10.1007/s004210100458. 
Robach, P., Calbet, J. A. L., Thomsen, J. J., Boushel, R., Mollard, P., Rasmussen, P. and Lundby, C. (2008) 'The ergogenic effect of recombinant human erythropoietin on VO2max depends on the severity of arterial hypoxemia.', PloS one. Public Library of Science, 3(8), p. e2996. doi: 10.1371/journal.pone.0002996.

Scherhag, A., Kaden, J. J. and Kentschke, E. (2005) 'Comparison of Impedance Cardiography and Thermodilution-Derived Measurements of Stroke Volume and Cardiac Output at Rest and During Exercise Testing', Cardiovascular Drugs and Therapy, 19, pp. 141-147.

Siebenmann, C., Rasmussen, P., Sørensen, H., Zaar, M., Hvidtfeldt, M., Pichon, a, Secher, N. H. and Lundby, C. (2015) 'Cardiac output during exercise: a comparison of four methods.', Scandinavian journal of medicine \& science in sports, 25(1), pp. e20-7. doi: $10.1111 /$ sms.12201.

Sramek, B. B. (1982) 'Cardiac output by electrical impedance.', Medical electronics, 13(2), pp. 93-7. Available at: http://www.ncbi.nlm.nih.gov/pubmed/10257596 (Accessed: 9 February 2016).

Tan, K. H., Lai, F. O. and Hwang, N. C. (2006) 'Measurement of cardiac output using Physio Flow with different positions of electrode placement.', Singapore medical journal, 47(11), pp. 967-70. Available at: http://www.ncbi.nlm.nih.gov/pubmed/17075665.

Tordi, N., Mourot, L., Matusheski, B. and Hughson, R. L. (2004) 'Measurements of cardiac output during constant exercises: comparison of two non-invasive techniques.', International journal of sports medicine, 25(2), pp. 145-9. doi: 10.1055/s-2004-819949.

Wang, E., Cruz, C., Pettersen, M. R., Hoff, J. and Helgerud, J. (2014) 'Comparison of thoracic bioimpedance with acetylene uptake for measuring cardiac output', International journal of sports medicine, 35(11), pp. 925-932. doi: 10.1055/s-0034-1367046.

Warburton, D. E. R., Haykowsky, M. J. F., Quinney, H. A., Humen, D. P. and Teo, K. K. (1999) 'Reliability and Validity of Measures of Cardiac Output During Incremental to Maximal Aerobic Exercise', Sports Medicine, 27(4), pp. 241-260. doi:

10.2165/00007256-199927040-00004. 